\title{
Photonics immunotherapy - A novel strategy for cancer treatment
}

\author{
Feifan Zhou*, Robert E. Nordquist ${ }^{\dagger}$ and Wei R. Chen*,†, \\ *Biophotonics Research Laboratory \\ Center for Interdisciplinary Biomedical Education Research \\ College of Mathematics and Science \\ University of Central Oklahoma \\ Edmond Oklahoma 73034, USA \\ ${ }^{\dagger}$ Immunophotonics Inc., St. Louis, Missouri 63108, USA \\ ¥wchen@uco.edu
}

Received 27 August 2015

Accepted 20 October 2015

Published 17 December 2015

\begin{abstract}
Photonics immunotherapy is a novel cancer treatment strategy that combines local phototherapy and immunotherapy. Phototherapy is a noninvasive or minimally invasive therapeutic strategy for local treatment of cancer, which can destroy tumor cells and release tumor antigens, inducing an in situ antitumor immune response. Immunotherapy, including the use of antibodies, vaccines, immunoadjuvants and cytokines, when combined with phototherapy, could bring a synergistic effect to stimulate a host immune response that effectuates a long-term antitumor immunity. This review will focus on the development of photonics immunotherapy and its systemic antitumor immunological effects.
\end{abstract}

Keywords: Photonics immunotherapy; cancer; phototherapy; immunotherapy; immune response.

\section{Introduction}

Cancer is a major public health problem in the world with an increased incidence rate over the past several decades. The cancer statistics report showed that a total of $1,658,370$ new cancer cases and 589,430 cancer deaths are projected to occur in the United States in 2015. ${ }^{1}$ Cancer is currently the second leading cause of death and is expected to surpass heart diseases as the leading cause of death in the next few years. During the past several decades in the fight against cancer, many novel treatment strategies have been developed, including targeted therapy, hormonal therapy and immunotherapy. Significant progress has been made in cancer immunotherapy during the past several decades, epitomized by naming cancer immunotherapy as the Breakthrough of the Year in 2013 by the journal Science. ${ }^{2}$

\$Corresponding author.

This is an Open Access article published by World Scientific Publishing Company. It is distributed under the terms of the Creative Commons Attribution 4.0 (CC-BY) License. Further distribution of this work is permitted, provided the original work is properly cited. 


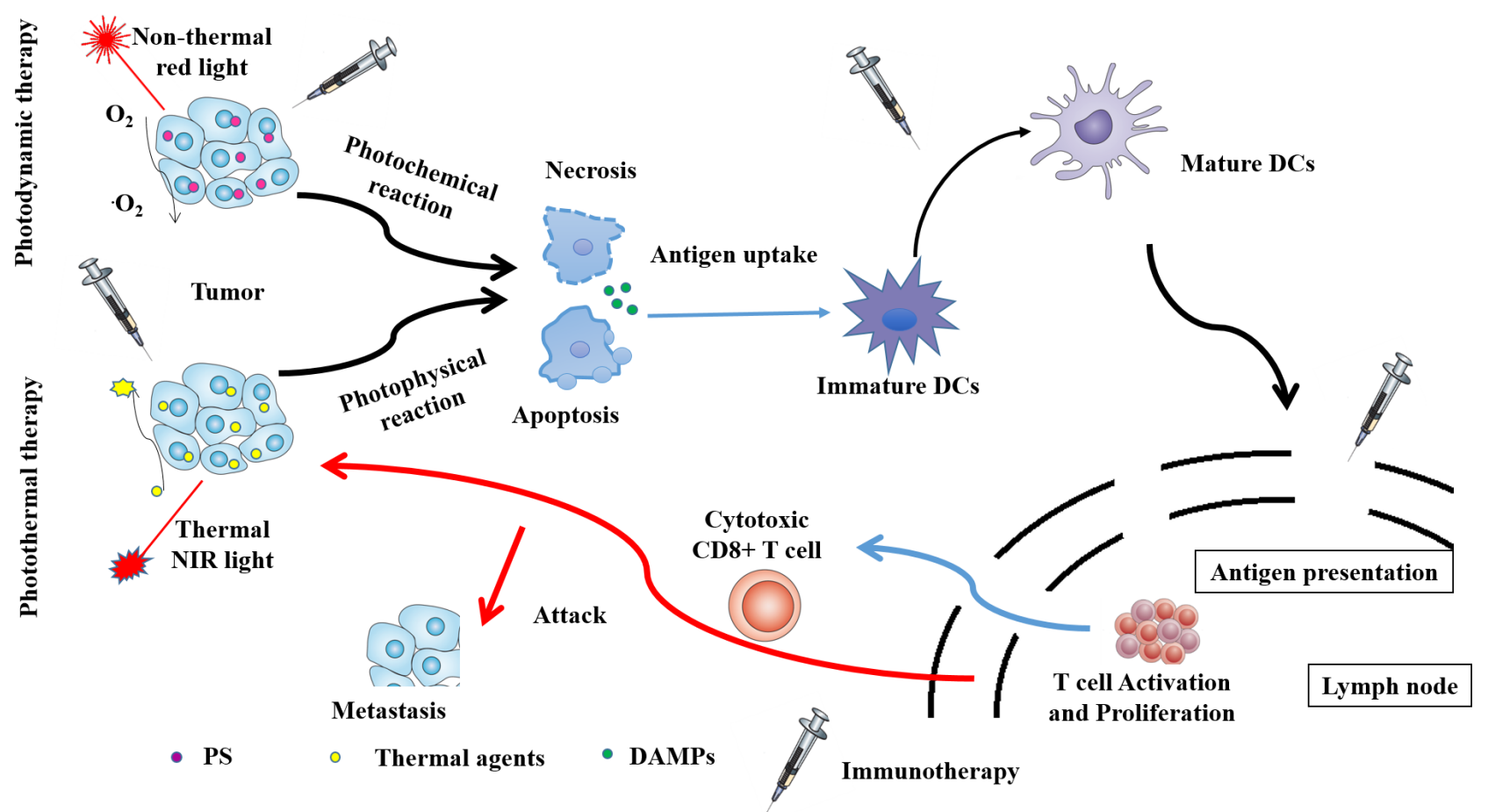

Fig. 1. Schematic of the systemic antitumor immune response induced by photonics immunotherapy.

It is believed that the ultimate control of cancer lies within the host immune surveillance and defense system. ${ }^{3,4}$ Many new strategies have been proposed, including cytokine therapy ${ }^{5}$ dendritic cell-based vaccines, ${ }^{6}$ checkpoint inhibitors and chimeric antigen receptor (CAR) T-cell therapy, ${ }^{7}$ which have begun to be used in clinical studies. The use of vaccines is another approach to immunotherapy..$^{8,9}$ These vaccines are usually made from a patient's own tumor cells or from substances taken from tumor cells, and are designed to treat cancers that have already developed by strengthening the body's natural defenses against the cancer. ${ }^{8,9}$ In 2010, the food and drug administration (FDA) approved sipuleucel-T (Provenge), a cancer vaccine for metastatic hormonerefractory prostate cancer (prostate cancer that has spread and is no longer responding to hormone treatment). ${ }^{10}$ Unlike a preventive vaccine, which is given to prevent disease, Provenge increases the immune system's ability to attack cancer cells in the body. This treatment has been shown to help certain men with prostate cancer live longer, though it does not cure the disease. ${ }^{11}$ It represents an important step forward in cancer treatment.

The ideal cancer therapy should not only destroy primary tumors, but also at the same time trigger the host immune system to recognize, track down, and destroy any remaining tumor cells, whether at or near the site of the primary tumors or at distant sites. In view of these desirable properties, some targeted phototherapy modalities, combined with immunotherapy, named as photonics immunotherapy (PIT), have been developed for metastatic cancers, including (PIT), laser immunotherapy (LIT) and other combinations. ${ }^{12-15}$ The schematic of the antitumor immune response induced by photonics immunotherapy is shown in Fig. 1.

\section{Phototherapy}

Phototherapy has been used for skin cancer for 3000 years. ${ }^{16-18}$ However, a systematic understanding of phototherapy has only been established over the past century. ${ }^{19}$ In Denmark, at the end of the 19th century, Niels Finsen developed phototherapy to treat diseases. He found that exposure to red-light prevents the formation and discharge of smallpox pustules, and can be used as an effective therapy against smallpox. ${ }^{18,20,21}$ He was awarded the Nobel Prize in Medicine and Physiology in 1903 for his contribution to the treatment of diseases, especially lupus vulgaris, with concentrated light radiation. ${ }^{21}$ This was the beginning of the modern light therapy, which has been developed for many diseases 
treatment, especially for cancer. After more a 100 years of research, photodynamic therapy (PDT) and photothermal therapy (PTT) are the most common used two methods of phototherapy for cancer. ${ }^{22-24}$

\subsection{Photodynamic therapy}

Photodynamic therapy is a clinically approved, minimally invasive therapeutic strategy for the local treatment of cancer. It involves three major elements: a targeted low-level visible light, nontoxic photosensitizers (PSs), and oxygen in tumor tissue. The PDT-induced photochemical reaction produces cytotoxic reactive oxygen species (ROS) to exert a selective cytotoxic activity toward malignant cells. ${ }^{12,18,22,25}$ PDT was the first drug-device combination approved by the US FDA almost two decades ago. ${ }^{25}$

Specifically, the procedure of PDT involves administration of a photosensitizing agent followed by irradiation at a wavelength corresponding to an absorbance band of the sensitizer, in the presence of oxygen; a photochemical reaction was initiated that culminates in the generation of a highly reactive product termed singlet oxygen $\left({ }^{1} \mathrm{O}_{2}\right)$. This can rapidly cause significant toxicity leading to cell death via apoptosis or necrosis. ${ }^{18,22,25}$ The lifetime of ${ }^{1} \mathrm{O}_{2}$ is very short (approximately 10-320 nanoseconds), limiting its diffusion to approximately 10 $\mathrm{nm}$ to $55 \mathrm{~nm}$ in cells. ${ }^{26}$ Thus, the mechanism of cell death induced by PDT depends on the intracellular localization of the photosensitizer. ${ }^{27,28}$

Due to the limitation of light penetration and the targeting of the PS, novel strategies in PDT have been developed over the past several decades. With the development of nanotechnology, many drugdelivery platforms have been applied to PDT, including liposomes, nanoemulsions, micelles, polymer nanoparticles, and silica nanoparticles. ${ }^{25,29-31}$ In some cases such as fullerenes and quantum dots, the actual nanoparticle itself acts as PS. ${ }^{32}$ Gold and silver nanoparticles can provide plasmonic enhancement of PDT. ${ }^{33}$ Furthermore, two-photon excitation or optical upconversion have been investigated instead of one-photon excitation to increase tissue penetration at longer wavelengths. ${ }^{34,35}$

\subsection{Photothermal therapy}

Photothermal therapy (PTT) is a developed therapeutic strategy for local treatment of cancer that uses heat generated from photon energy to destroy tumor cells, which could be highly specific, much less invasive, and rather effective due to the intensive light beam directly focused on the target tumor. ${ }^{36-38}$ Heating sources, including near infrared or visible light, radiofrequency waves, microwaves, and ultrasound waves, have been used to induce moderate temperature rise in a specific target region to destroy cancer cells. ${ }^{38}$ This kind of thermal therapy is currently used in the treatment of patients with solid tumors affecting various organs, such as the liver, kidney, lung, adrenal gland, prostate and bone. ${ }^{39}$

During irradiation on tumor tissue, the chromophores in the light path can also absorb energy, reducing the effectiveness of heat deposition within tumor cells and increasing nonspecific injury of adjacent healthy tissue. ${ }^{40}$ To further enhance the thermal efficacy on tumor tissue, selective photothermal interaction using laser and in situ lightabsorbing dye was initially developed. Specifically, an $805 \mathrm{~nm}$ laser was used in conjunction with indocyanine green (ICG), since biological tissues permit a deep penetrability with low absorption of near-infrared (NIR) photons, and ICG solution has a high absorption peak around $800 \mathrm{~nm}$, which made it an ideal candidate for selective PTT. ${ }^{24,41,42}$

Recently, PTT has attracted renewed attention in the battle against cancer because of the development of novel photothermally sensitized agents - nanomaterials, including gold nanoparticles, gold nanorods, carbon nanotubes, graphene and others. ${ }^{38,43-47}$ With strong optical absorbance in the NIR region, nanomaterials could transfer photo energy of NIR laser and radiofrequency into heat energy to enhance thermal destruction. ${ }^{38,40}$

\subsection{Immune response induced by phototherapy}

The first direct effect of phototherapy (PDT and PPT) is their cytotoxicity on tumor cells, either induced by ROS production or by temperature increase. The second but perhaps more important effect of PDT or PPT is the increase of immunogenicity of the tumor due to the release of damaged associated molecular patterns (DAMPs) and celldeath-associated molecular patterns (CDAMPs) that can be detected by the innate immunity alert elements. ${ }^{39,48-53}$ Phototherapy has been shown to 
induce the release of heat shock proteins (HSP) (e.g., HSP47, 60, 70), stress-inducible proteins GRP78, 94 and haem oxygenase from cancer cells. ${ }^{54-58}$ Antigen presenting cells (APCs), particularly dendritic cells (DCs), can capture these antigens, migrate to lymph nodes, and present the antigens to $\mathrm{T}$ cells to induce antitumor immune responses. ${ }^{39,59,60}$

One of the most important cellular factors induced by phototherapy is HSP70. As a chaperone, HSP70 is effectively induced after stress, working as an endogenous danger signal in the immune system. ${ }^{61,62}$ HSP70 can chaperon unfolded proteins forming HSP-peptide complexes that can be released from damaged cells to promote the crosspresentation of HSP-bound peptide antigens to major histocompatibility complex (MHC) class I molecules in DCs, leading to efficient induction of antigen-specific cytotoxic $\mathrm{T}$ lymphocytes. ${ }^{63-66}$ Phototherapy could enhance HSP expression in the tumor cells, particularly on the cell surface of apoptotic cells, which could be recognized by APCs through toll like receptor (TLRs), followed by cytokine release via $\mathrm{Myd} 88$ and $\mathrm{NF}-\mathrm{kB}$ signaling pathways. ${ }^{67-70}$

In particular, phototherapy, as a promising cancer treatment strategy that uses a local, selective photothermal or photochemical interaction on target tumor to release tumor antigens, creates an antigen source that acts as an in situ cancer vaccine. ${ }^{71}$ The roles of HSPs in stimulating both innate immunity and adaptive immunity can explain at least in part the molecular mechanism by which phototherapy bolsters the host immune system. ${ }^{72}$

\section{Photoimmunotherapy}

Phototherapy can induce tumor cell death and create an antigen source through local intervention. Concomitantly, this target treatment strategy has been combined with immunotherapy that can promote antigen uptake and presentation, thus triggering a specific antitumor immunity. These immunotherapies include antibodies, cytokines and other proteins and peptides. ${ }^{14,15,73,74}$

\subsection{Photoimmunotherapy using anti- body for photosensitizer delivery}

To overcome the limitations inherent in PDT, PIT, using a monoclonal antibody (mAb)-targeted PS and red-light, has been developed, as a novel target phototherapy approches. ${ }^{74,75}$ PIT was developed by Hasan et al. to treat human ovarian cancer cells. ${ }^{74,76-78}$ The photosensitizer chlorin e6 was conjugated to the $\mathrm{F}\left(\mathrm{ab}^{\prime}\right) 2$ fragment of the murine monoclonal antibody OC-125, which is directed against antigen CA 125 that is expressed on $80 \%$ of nonmucinous ovarian tumors. ${ }^{79-81}$ A chlorin derivative conjugated to OC-125 was shown to be selectively phototoxic to ovarian cancer and other CA 125-positive cells in vitro and ex vivo. ${ }^{78} \mathrm{PIT}$ was also used to treat hepatic metastases of colorectal cancer in an orthotopic murine xenograft model using the murine monoclonal antibody $17.1 \mathrm{~A}$ conjugated to PS chlorine $6 .^{82}$

Recently, a new type PIT has been developed by Kobayashi et al. known as NIR-PIT, using a targetspecific PS based on a NIR phthalocyanine dye, IR700, conjugated to mAb targeting epidermal growth factor receptors (EGFR). ${ }^{15}$ The treatment approach of NIR-PIT not only increased the target efficacy of PS, but also improved the penetration of PDT using NIR light. EGFRs are overexpressed on the cell surface of several cancers including lung, colon, head and neck, and esophageal cancers. ${ }^{83-86}$ The targeting monoclonal antibodies, cetuximab, and panitumumab, have been approved by the US FDA. ${ }^{87-90}$ In the procedure of NIR-PIT, the PS, IR700 (a silica based phthalocyanine dye), was conjugated to an antibody and activated after cell binding by NIR light at $690 \mathrm{~nm}$. In vitro studies have shown that mAb-IR700 conjugate is highly cell-specific to the target cell, and nontoxic on the nonexpressing cells immediately adjacent to targeted cells. ${ }^{91}$ When exposed to NIR light, mAbIR700 conjugate could quickly result in rapid and irreversible damage to the cell membrane, leading to necrotic cell death. ${ }^{15,92-95}$

\subsection{Laser immunotherapy}

Laser immunotherapy (LIT) first proposed by Chen et $a{ }^{14}{ }^{14}$ is a combination therapy of phototherapy and immunotherapy, which utilizes a local intervention to induce a systemic antitumor immunity. ${ }^{14}$ The two principles underlying this therapy are (1) the local destruction of tumor cells resulting from direct delivery of laser energy into the tumor, which liberates tumor antigens and in itself induces a local immune response, and (2) the local administration of an immunoadjuvant to elicit a 
much stronger systemic immune response. The fundamental mechanism behind LIT is the activation of APCs, such as DCs, and subsequent exposure of the activated APCs to tumor antigens in vivo so that a tumor-specific $\mathrm{T}$ cell response is induced. LIT may therefore be considered an in situ autologous cancer vaccine (trademarked as inCVAX) that utilizes whole tumor cells as the source of tumor antigens without the need for ex vivo preparations. ${ }^{96}$

The early LIT approach combined three major components: a NIR laser (805 nm), a light-absorbing agent (ICG) to enhance light absorption in the tumor tissue, and an immunoadjuvant to further enhance immune response after the photothermal treatment. ${ }^{15,97-100}$ LIT has shown great promise in a number of preclinical studies. ${ }^{73,101,102}$ It has consistently demonstrated immediate photothermal destruction of cancer cells, as well as an immune response against the treated primary tumors and untreated distant metastases. ${ }^{14,73,103-105}$ In a metastatic rat mammary tumor model known as DMBA-4, rats treated with LIT reached a $38 \%$ long-term (more than 120 days) survival rate, while all animals in the untreated control died within 40 days with multiple metastases. ${ }^{106}$ Among the cured animals, untreated metastases also disappeared. ${ }^{102}$ LIT cured animals demonstrated memory in that they could withstand repeated rechallenge by tumor cells of the same origin at up to 10 times the initial cell number. ${ }^{73}$ Neither prior surgical removal nor immunization with tumor lysate could provide protection against tumor rechallenge, ${ }^{101}$ suggesting that LIT is capable of enhancing tumor immunogenicity.

LIT has been applied in clinical trials for latestage, metastatic melanoma and breast cancer patients. The data indicate that local LIT treatment is capable of reducing and eliminating treated primary tumors as well as untreated metastases in the lungs, significantly prolonging patient survival. ${ }^{107-110}$

Researchers also combined PDT with immunoadjuvant, such as Photofrin-PDT with zymosan and methyl aminolevulinate (PPIX)-PDT with imiquimod in cancer treatment. ${ }^{111,112}$ To overcome the obstacles of deeper tumors and highly pigmented skins, the procedure of LIT has been improved by removing the ICG component and performing interstitial laser irradiation intratumoral for direct photothermal application. ${ }^{113}$
Recently, immunologically modified nano-systems have been developed using immunoadjuvants and nanomaterials to enhance the therapeutic effects of LIT, ${ }^{114,115}$ such as the new structure system formed with immunoadjuvant, glycated chitosan (GC), as a surfactant of single-walled carbon nanotubes (SWNTs), ${ }^{114}$ and chitosan-coated hollow copper sulfide nanoparticles, using $\mathrm{CuS}$ nanoparticles coated with immunoadjuvant, cytosineguanine $(\mathrm{CpG})$ motifs. ${ }^{115}$ These new nano-systems could retain both optical properties of nanomaterials and immunological function of adjuvants, representing promising treatment modalities combined with laser irradiation to induce systemic antitumor response through a local intervention. ${ }^{114,115}$

\subsection{Combination of immunostimulation and phototherapy}

Other immunostimulatory agents combined with phototherapy can be mainly divided into two classes: microbial vaccines and cytokines.

The first class of agents derived from microbial, such as OK-432 that was derived from penicillin killed streptococcal bacteria and corynebacterium parvum $(\mathrm{CP})$ which is a killed bacterial vaccine, has been used to combine with PDT. ${ }^{116}$ Haematoporphyrin derivative (HPD)-mediated PDT has been used in combination with OK-432 to treat NR-S1 mouse squamous cell carcinoma, or with $\mathrm{CP}$ to treat mouse subcutaneous bladder cancer. ${ }^{117,118}$ Both OK-432 and CP combined with HPD-PDT resulted in similar results showing that the administration of OK-432 or CP, prior to PDT, lead to significantly improved outcomes; however, no significant differences occurred after PDT. ${ }^{117,118}$ Korbelik et al. combined Bacillus Calmette-Guérin (BCG) with PDT using six different PSs (Photofrin, benzoporphyrin derivative (BPD), mTHPC, ce6, $\mathrm{ZnPC}$, and lutetium texaphyrin), or combined mycobacterial cell wall extract (MCWE) with PDT using four different PSs (Photofrin, BPD, mTHPC, and $\mathrm{ZnPC}$ ), in the treatment of murine subcutaneous EMT6 tumor model. Their results showed that the cure rates were significantly higher in mice either treated with BCG or MCWE combined PDT, regardless of which PS was used. ${ }^{119,120}$

The second class of combination therapies concerns the administration of cytokines with 
Photofrin-PDT, such as granulocyte colony stimulating factor (G-CSF) on colo 26 and Lewis lung carcinomas tumor models, granulocyte-macrophage colony stimulating factors (GM-CSF) on SCCVII tumor models, and tumor necrosis factor $(\mathrm{TNF} \alpha)$ on SMT-F adenocarcinoma tumor model. ${ }^{121-123}$ All administration of cytokines can enhance the therapeutic effects. Other phototherapies also have been developed in combination with cytokines, such as radiofrequency with interleukin 12 (IL-12) in the treatment of murine colon adenocarcinoma, or with IL-17 and IL-15 in the treatment of murine breast tumors. ${ }^{124,125}$

\section{Prospect}

Phototherapy, a medicinal method with a history of more than 3000 years, has been given a new life with the technological breakthroughs of a modern era, such as using lasers as the light sources, PS and nanoparticles as the in situ executors. Today, phototherapy has been widely used in either diagnosis or therapeutics. The future of phototherapy in biomedicine continues to brighten.

Riding high on the new wave of immunotherapy, phototherapy shows great promise in targeting the root cause of many diseases by immunologically delivering and chronically releasing diagnostic and therapeutic agents, and by inducing tissue immunological response and enhancing synergizing immunotherapy. Phototherapy itself can initiate immunological responses, selective photothermal and photochemical interactions to eliminate tumor cells and release tumor antigens, and create an in situ cancer vaccine; whereas immunotherapy endeavors to stimulate a host immune response that effectuates long-lived tumor destruction. The synergistic effects of PIT raise the possibility to improve clinical outcomes. We believe that in the coming years there will be great advances in the area of PIT, with better understanding of the induction of antitumor immune response by phototherapy and further development of immunotherapy.

What we learned from PIT is only the tip of the iceberg; more exploration is needed. Particularly interesting to researchers is how to increase the effectiveness of photophysical effects, immunological responses, and how to optimize the synergy between phototherapy and immunotherapy. While many challenges are ahead, the promising clinical outcomes of PIT remain as exciting facts to researchers, physicians and entrepreneurs for years to come.

\section{Acknowledgments}

This study was supported in part by a grant from the US National Institutes of Health (R21 EB0155091-01). The authors also thank Janet S. Clark for clerical and editorial assistance.

\section{References}

1. R. L. Siegel, K. D. Miller, A. Jemal, "Cancer statistics, 2015," CA Cancer J. Clin. 65, 5-29 (2015).

2. J. Couzin-Frankel, "Cancer immunotherapy," Science 342, 1432-1433 (2013).

3. O. J. Finn, "Cancer immunology," N. Engl. J. Med. 358, 2704-2715 (2008).

4. J. N. Blattman, P. D. Greenberg, "Cancer immunotherapy: A treatment for the masses," Science 305, 200-205 (2004).

5. A. Carpi, A. Nicolini, A. Antonelli, P. Ferrari, G. Rossi, "Cytokines in the management of high risk or advanced breast cancer: An update and expectation," Curr. Cancer Drug Targets 9, 888903 (2009).

6. E. A. Eksioglu, S. Eisen, V. Reddy, "Dendritic cells as therapeutic agents against cancer," Front. Biosci. (Landmark Ed.) 15, 321-347 (2010).

7. J. Couzin-Frankel, "The dizzying journey to a new cancer arsenal," Science 340, 1514-1518 (2013).

8. I. Melero, G. Gaudernack, W. Gerritsen, C. Huber, G. Parmiani, S. Scholl, N. Thatcher, J. Wagstaff, C. Zielinski, I. Faulkner, H. Mellstedt, "Therapeutic vaccines for cancer: An overview of clinical trials," Nat. Rev. Clin. Oncol. 11, 509-524 (2014).

9. C. A. Klebanoff, N. Acquavella, Z. Yu, N. P. Restifo, "Therapeutic cancer vaccines: Are we there yet?," Immunol. Rev. 239, 27-44 (2011).

10. J. H. Tanne, "FDA approves prostate cancer "vaccine"," BMJ 340, c2431 (2010).

11. H. E. Kaiser, B. Bodey, B. Bodey Jr., S. E. Siegel, "Failure of cancer vaccines: The significant limitations of this approach to immunotherapy," $A n$ ticancer Res. 20, 2665-2676 (2000).

12. A. P. Castano, P. Mroz, M. R. Hamblin, "Photodynamic therapy and anti-tumour immunity," Nat. Rev. Cancer 6, 535-545 (2006).

13. G. Dranoff, M. Vanneman, "Combining immunotherapy and targeted therapies in cancer treatment," Nat. Rev. Cancer 12, 237-251 (2012). 
14. W. R. Chen, R. L. Adams, R. Carubelli, R. E. Nordquist, "Laser-photosensitizer assisted immunotherapy: A novel modality in cancer treatment," Cancer Lett. 115, 25-30 (1997).

15. M. Mitsunaga, M. Ogawa, N. Kosaka, L. T. Rosenblum, P. L. Choyke, H. Kobayashi, "Cancer cell-selective in vivo near infrared photoimmunotherapy targeting specific membrane molecules," Nat. Med. 17, 1685-1691 (2011).

16. M. D. Daniell, J. S. Hill, "A history of photodynamic therapy," Aust. N Z J. Surg. 61, 340-348 (1991).

17. R. Ackroyd, C. Kelty, N. Brown, M. Reed, "The history of photodetection and photodynamic therapy," Photochem. Photobiol. 74, 656-669 (2001).

18. D. E Dolmans, D. Fukumura, R. K. Jain, "Photodynamic therapy for cancer," Nat. Rev. Cancer 3, 380-387 (2003).

19. S. Zhang, N. Jia, P. Shao, Q. Tong, X. Q. Xie, M. Bai, "Target-selective phototherapy using a ligandbased photosensitizer for type 2 cannabinoid receptor," Chem. Biol. 21, 338-344 (2014).

20. N. R. Finsen, Phototherapy, Edward Arnold: London (1901).

21. A. Grzybowski, K. Pietrzak, "From patient to discoverer-Niels Ryberg Finsen (1860-1904) The founder of phototherapy in dermatology," Clin. Dermatol. 30, 451-455 (2012).

22. T. J. Dougherty, C. J. Gomer, B.W. Henderson, G. Jori, D. Kessel, M. Korbelik, J. Moan, Q. Peng, "Photodynamic therapy," J. Natl. Cancer Inst. 90, 889-905 (1998).

23. S. Wu, F. Zhou, Y. Wei, W. R. Chen, Q. Chen, D. Xing, "Cancer phototherapy via selective photoinactivation of respiratory chain oxidase to trigger a fatal superoxide anion burst," Antioxid. Redox Signal. 20, 733-746 (2014).

24. W. R. Chen, R. L. Adams, K. E. Bartels, R. E. Nordquist, "Chromophore-enhanced in vivo tumor cell destruction using an 808-nm diode laser," Cancer Lett. 94, 125-131 (1995).

25. P. Agostinis, K. Berg, K. A. Cengel, T. H. Foster, A. W. Girotti, S. O. Gollnick, S. M. Hahn, M. R. Hamblin, A. Juzeniene, D. Kessel, M. Korbelik, J. Moan, P. Mroz, D. Nowis, J. Piette, B. C. Wilson, J. Golab, "Photodynamic therapy of cancer: An update," CA Cancer J. Clin. 61, 250-281 (2011).

26. J. S. Dysart, M. S. Patterson, "Characterization of Photofrin photobleaching for singlet oxygen dose estimation during photodynamic therapy of MLL cells in vitro," Phys. Med. Biol. 50, 2597-2616 (2005).

27. J. Moan, K. Berg, E. Kvam, A. Western, Z. Malik, A. Rück, H. Schneckenburger, "Intracellular localization of photosensitizers," Ciba Found. Symp. 146, 95-107 (1989).

28. D. Kessel, Y. Luo, Y. Deng, C. K. Chang, "The role of subcellular localization in initiation of apoptosis by photodynamic therapy," Photochem. Photobiol. 65, 422-426 (1997).

29. Y.Y. Huang, S. K. Sharma, T. Dai, H. Chung, A. Yaroslavsky, M. Garcia-Diaz1, J. Chang, L. Y. Chiang, M. R. Hamblin, "Can nanotechnology potentiate photodynamic therapy?," Nanotechnol. Rev. 1, 111-146 (2012).

30. D. K. Chatterjee, L. S. Fong, Y. Zhang, "Nanoparticles in photodynamic therapy: An emerging paradigm," Adv. Drug Deliv. Rev. 60, 1627-1637 (2008).

31. A. S. Derycke, P. A. de Witte, "Liposomes for photodynamic therapy," Adv. Drug Deliv. Rev. 56, 17-30 (2004).

32. Z. Zhu, Z. Tang, J. A. Phillips, R. Yang, H. Wang, W. Tan, "Regulation of singlet oxygen generation using single-walled carbon nanotubes," J. Am. Chem. Soc. 130, 10856-10857 (2008).

33. Y. Li, T. Wen, R. Zhao, X. Liu, T. Ji, H. Wang, X. Shi, J. Shi, J. Wei, Y. Zhao, X. Wu, G. Nie, "Localized electric field of plasmonic nanoplatform enhanced photodynamic tumor therapy," ACS Nano. 8, 11529-11542 (2014).

34. J. R. Starkey, A. K. Rebane, M. A. Drobizhev, F. Meng, A. Gong, A. Elliott, K. McInnerney, C. W. Spangler, "New two-photon activated photodynamic therapy sensitizers induce xenograft tumor regressions after near-IR laser treatment through the body of the host mouse," Clin. Cancer Res. 14, 6564-6573 (2008).

35. C. Wang, L. Cheng, Z. Liu, "Upconversion nanoparticles for photodynamic therapy and other cancer therapeutics," Theranostics 3, 317-330 (2013).

36. J. M. Brunetaud, S. Mordon, V. Maunoury, C. Beacco, "Non-PDT Uses of lasers in oncology," Lasers Med Sci. 10, 3-8 (1995).

37. C. Liang, S. Diao, C. Wang, H. Gong, T. Liu, G. Hong, X. Shi, H. Dai, Z. Liu, "Tumor metastasis inhibition by imaging-guided photothermal therapy with single-walled carbon nanotubes," $A d v$. Mater. 26, 5646-5652 (2014).

38. X. Huang, M. A. El-Sayed, "Plasmonic photothermal therapy (PPTT)," Alexandria J. Med. 47, 1-9 (2011).

39. M. R. Hamblin, Y.-Y. Huang, Handbook of Photomedicine, CRC Press, LLC (2013).

40. F. Zhou, D. Xing, Z. Ou, B. Wu, D. E. Resasco, W. R. Chen, "Cancer photothermal therapy in the near-infrared region by using single-walled carbon nanotubes," J. Biomed. Opt. 14, 021009 (2009). 
41. W. R. Chen, R. L. Adams, S. Heaton, D. T. Dickey, K. E. Bartels, R. E. Nordquist, "Chromophoreenhanced laser-tumor tissue photothermal interaction using $808 \mathrm{~nm}$ diode laser," Cancer Lett. 88, 15-19 (1995).

42. W. R. Chen, R. L. Adams, A. K. Higgins, K. E. Bartels, R. E. Nordquist, "Photothermal effects on murine mammary tumors using indocyanine green and an 808-nm diode laser: An in vivo efficacy study," Cancer Lett. 98, 169-173 (1996).

43. L. R. Hirsch, R. J. Stafford, J. A. Bankson, S. R. Sershen, B. Rivera, R. E. Price, J. D. Hazle, N. J. Halas, J. L. West, "Nanoshell-mediated near-infrared thermal therapy of tumors under magnetic resonance guidance," Proc. Natl. Acad. Sci. USA 100, 13549-13554 (2003).

44. F. Zhou, S. Wu, B. Wu, W. R. Chen, D. Xing, "Mitochondria-targeting single-walled carbon nanotubes for cancer photothermal therapy," Small 7, 2727-2735 (2011).

45. X. Huang, I. H. El-Sayed, W. Qian, M. A. El-Sayed, "Cancer cell imaging and photothermal therapy in the near-infrared region by using gold nanorods," $J$. Am. Chem. Soc. 128, 2115-2120 (2006).

46. K. Yang, S. Zhang, G. Zhang, X. Sun, S. T. Lee, Z. Liu, "Graphene in mice: Ultrahigh in vivo tumor uptake and efficient photothermal therapy," Nano Lett. 10, 3318-3323 (2010).

47. L. Cheng, K. Yang, Y. Li, J. Chen, C. Wang, M. Shao, S. T. Lee, Z. Liu, "Facile preparation of multifunctional upconversion nanoprobes for multimodal imaging and dual-targeted photothermal therapy," Angew. Chem. Int. Ed. Engl. 50, 73857390 (2011).

48. A. D. Garg, D. Nowis, J. Golab, P. Vandenabeele, D. V. Krysko, P. Agostinis, "Immunogenic cell death, DAMPs and anticancer therapeutics: An emerging amalgamation," Biochim. Biophys. Acta. 1805, 53-71 (2010).

49. M. H. den Brok, R. P. Sutmuller, R. van der Voort, E. J. Bennink, C. G. Figdor, T. J. Ruers, G. J. Adema, "In situ tumor ablation creates an antigen source for the generation of antitumor immunity," Cancer Res. 64, 4024-4029 (2004).

50. M. Korbelik, "PDT-associated host response and its role in the therapy outcome," Lasers Surg. Med. 38, 500-508 (2006).

51. A. D. Garg, D. Nowis, J. Golab, P. Agostinis, "Photodynamic therapy: Illuminating the road from cell death towards anti-tumour immunity," Apoptosis 15, 1050-1071 (2010).

52. P. Mroz, J. T. Hashmi, Y. Y. Huang, N. Lange, M. R. Hamblin, "Stimulation of anti-tumor immunity by photodynamic therapy," Expert Rev. Clin. Immunol. 7, 75-91 (2011).
53. H. G. Zhang, K. Mehta, P. Cohen, C. Guha, "Hyperthermia on immune regulation: A temperature's story," Cancer Lett. 271, 191-204 (2008).

54. A. K. Verrico, A. K. Haylett, J. V. Moore, "In vivo expression of the collagen-related heat shock protein HSP47, following hyperthermia or photodynamic therapy," Lasers Med. Sci. 16, 192-198 (2001).

55. J. G. Hanlon, K. Adams, A. J. Rainbow, R. S. Gupta, G. Singh, "Induction of Hsp60 by Photofrin-mediated photodynamic therapy," J. Photochem. Photobiol. B 64, 55-61 (2001).

56. T. Verwanger, R. Sanovic, F. Aberger, A. M. Frischauf, B. Krammer, "Gene expression pattern following photodynamic treatment of the carcinoma cell line A-431 analysed by cDNA arrays," Int. J. Oncol. 21, 1353-1359 (2002).

57. C. J. Gomer, A. Ferrario, N. Rucker, S. Wong, A. S. Lee, "Glucose regulated protein induction and cellular resistance to oxidative stress mediated by porphyrin photosensitization," Cancer Res. 51, 6574-6579 (1991).

58. D. Nowis, M. Legat, T. Grzela, J. Niderla, E. Wilczek, G. M. Wilczynski, E. Głodkowska, P. Mrówka, T. Issat, J. Dulak, A. Józkowicz, H. Waś, M. Adamek, A. Wrzosek, S. Nazarewski, M. Makowski, T. Stokłosa, M. Jakóbisiak, J. Gołab, "Heme oxygenase-1 protects tumor cells against photodynamic therapy-mediated cytotoxicity," Oncogene 25, 3365-3374 (2006).

59. A. Mukhopadhaya, J. Mendecki, X. Dong, L. Liu, S. Kalnicki, M. Garg, A. Alfieri, C. Guha, "Localized hyperthermia combined with intratumoral dendritic cells induces systemic antitumor immunity," Cancer Res. 67, 7798-7806 (2007).

60. M. N. Rylander, Y. Feng, J. Bass, K. R. Diller, "Heat shock protein expression and injury optimization for laser therapy design," Lasers Surg. Med. 39, 731-746 (2007).

61. Z. Prohászka, "Chaperones as part of immune networks," Adv. Exp. Med. Biol. 594, 159-166 (2007).

62. P. Srivastava, "Interaction of heat shock proteins with peptides and antigen presenting cells: Chaperoning of the innate and adaptive immune responses," Annu. Rev. Immunol. 20, 395-425 (2002).

63. T. Chen, J. Guo, C. Han, M. Yang, X. Cao, "Heat shock protein 70 , released from heat-stressed tumor cells, initiates antitumor immunity by inducing tumor cell chemokine production and activating dendritic cells via TLR4 pathway," J. Immunol. 182, 1449-1459 (2009).

64. J. Gong, Y. Zhang, J. Durfee, D. Weng, C. Liu, S. Koido, B. Song, V. Apostolopoulos, S. K. 
Calderwood, "A heat shock protein 70-based vaccine with enhanced immunogenicity for clinical use," J. Immunol. 184, 488-496 (2010).

65. M. Nishikawa, S. Takemoto, Y. Takakura, "Heat shock protein derivatives for delivery of antigens to antigen presenting cells," Int. J. Pharm. 354, 2327 (2008).

66. T. Torigoe, Y. Tamura, N. Sato, "Heat shock proteins and immunity: Application of hyperthermia for immunomodulation," Int. J. Hyperthermia. 25, 610-616 (2009).

67. M. Korbelik, J. Sun, I. Cecic, "Photodynamic therapy-induced cell surface expression and release of heat shock proteins: Relevance for tumor response," Cancer Res. 65, 1018-1026 (2005).

68. F. Zhou, D. Xing, W. R. Chen, "Dynamics and mechanism of HSP70 translocation induced by photodynamic therapy treatment," Cancer Lett. 264, 135-144 (2008).

69. F. Zhou, D. Xing, W. R. Chen, "Regulation of HSP70 on activating macrophages using PDT induced apoptotic cells," Int. J. Cancer 125, 13801389 (2009).

70. S. Song, F. Zhou, D. Xing, W. R. Chen, "PDTinduced HSP70 externalization up-regulates NO production via TLR2 signal pathway in macrophages," FEBS Lett. 587, 128-135 (2013).

71. R. F. Sánchez-Ortiz, N. Tannir, K. Ahrar, C. G. Wood, "Spontaneous regression of pulmonary metastases from renal cell carcinoma after radio frequency ablation of primary tumor: An in situ tumor vaccine?," J. Urol. 170, 178-179 (2003).

72. A. Murshid, J. Gong, S. K. Calderwood, "The role of heat shock proteins in antigen cross presentation," Front. Immunol. 3, 63 (2012).

73. W. R. Chen, H. Liu, J. W. Ritchey, K. E. Bartels, M. D. Lucroy, R. E. Nordquist, "Effect of different components of laser immunotherapy in treatment of metastatic tumors in rats," Cancer Res. 62, 4295-4299 (2002).

74. B. A. Goff, M. Bamberg, T. Hasan, "Photoimmunotherapy of human ovarian carcinoma cells ex vivo," Cancer Res. 51, 4762-4767 (1991).

75. D. Mew, C. K. Wat, G. H. Towers, J. G. Levy, "Photoimmunotherapy: Treatment of animal tumors with tumor-specific monoclonal antibodyhematoporphyrin conjugates," J. Immunol. 130, 1473-1477 (1983).

76. B. A. Goff, U. Hermanto, J. Rumbaugh, J. Blake, M. Bamberg, T. Hasan, "Photoimmunotherapy and biodistribution with an OC125-chlorin immunoconjugate in an in vivo murine ovarian cancer model," Br. J. Cancer 70, 474-480 (1994).
77. B. A. Goff, J. Blake, M. P. Bamberg, T. Hasan, "Treatment of ovarian cancer with photodynamic therapy and immunoconjugates in a murine ovarian cancer model," Br. J. Cancer 74, 1194-1198 (1996).

78. M. R. Hamblin, J. L. Miller, T. Hasan, "Effect of charge on the interaction of site-specific photoimmunoconjugates with human ovarian cancer cells," Cancer Res. 56, 5205-5210 (1996).

79. R. C. Bast Jr., M. Feeney, H. Lazarus, L. M. Nadler, R. B. Colvin, R. C. Knapp, "Reactivity of a monoclonal antibody with human ovarian carcinoma," J. Clin. Invest. 68, 1331-1337 (1981).

80. R. C. Bast Jr., T. L. Klug, E. St John, E. Jenison, J. M. Niloff, H. Lazarus, R. S. Berkowitz, T. Leavitt, C. T. Griffiths, L. Parker, V. R. Zurawski Jr., R. C. Knapp, "A radioimmunoassay using a monoclonal antibody to monitor the course of epithelial ovarian cancer," N. Engl. J. Med. 309, 883-887 (1983).

81. M. N. Hosono, K. Endo, H. Sakahara, Y. Watanabe, T. Saga, T. Nakai, M. Hosono, T. Nakajima, Y. Onoyama, J. Konishi, "Different antigenic nature in apparently healthy women with high serum CA 125 levels compared with typical patients with ovarian cancer," Cancer 70, 2851-2856 (1992).

82. M. Del Governatore, M. R. Hamblin, C. R. Shea, I. Rizvi, K. G. Molpus, K. K Tanabe, T. Hasan, "Experimental photoimmunotherapy of hepatic metastases of colorectal cancer with a 17.1A chlorin(e6) immunoconjugate," Cancer Res. 60, 4200-4205 (2000).

83. C. Eng, "The evolving role of monoclonal antibodies in colorectal cancer: Early presumptions and impact on clinical trial development," Oncologist 15, 73-84 (2010).

84. E. Norguet, L. Dahan, J. F. Seitz, "Targetting esophageal and gastric cancers with monoclonal antibodies," Curr. Top. Med. Chem. 12, 1678$1682(2012)$.

85. L. Vecchione, B. Jacobs, N. Normanno, F. Ciardiello, S. Tejpar, "EGFR-targeted therapy," Exp. Cell Res. 317, 2765-2771 (2011).

86. T. E. Stinchcombe, M. A. Socinski, "Targeted therapies: Biomarkers in NSCLC for selecting cetuximab therapy," Nat. Rev. Clin. Oncol. 7, $426-428$ (2010).

87. N. Tebbutt, M. W. Pedersen, T. G. Johns, "Targeting the ERBB family in cancer: Couples therapy," Nat. Rev. Cancer 13, 663-673 (2013).

88. T. A. Waldmann, "Immunotherapy: Past, present and future," Nat. Med. 9, 269-277 (2003).

89. J. M. Reichert, C. J. Rosensweig, L. B. Faden, M. C. Dewitz, "Monoclonal antibody successes in the clinic," Nat. Biotechnol. 23, 1073-1088 (2005). 
90. K. Sato, R. Watanabe, H. Hanaoka, T. Harada, T. Nakajima, I. Kim, C. H. Paik, P. L. Choyke, H. Kobayashi, "Photoimmunotherapy: Comparative effectiveness of two monoclonal antibodies targeting the epidermal growth factor receptor," Mol. Oncol. 8, 620-632 (2014).

91. M. Mitsunaga, T. Nakajima, K. Sano, P. L. Choyke, H. Kobayashi, "Near-infrared theranostic photoimmunotherapy (PIT): Repeated exposure of light enhances the effect of immunoconjugate," Bioconjug. Chem. 23, 604-609 (2012).

92. M. Mitsunaga, T. Nakajima, K. Sano, G. KramerMarek, P. L. Choyke, H. Kobayashi, "Immediate in vivo target-specific cancer cell death after near infrared photoimmunotherapy," BMC Cancer 12, 345 (2012).

93. T. Nakajima, K. Sano, M. Mitsunaga, P. L. Choyke, H. Kobayashi, "Real-time monitoring of in vivo acute necrotic cancer cell death induced by near infrared photoimmunotherapy using fluorescence lifetime imaging," Cancer Res. 72, 46224628 (2012).

94. T. Nakajima, K. Sano, P. L. Choyke, H. Kobayashi, "Improving the efficacy of photoimmunotherapy (PIT) using a cocktail of antibody conjugates in a multiple antigen tumor model," Theranostics 3, 357-365 (2013).

95. K. Sato, T. Nagaya, P. L. Choyke, H. Kobayashi, "Near infrared photoimmunotherapy in the treatment of pleural disseminated NSCLC: preclinical experience," Theranostics 5, 698-709 (2015).

96. F. Zhou, X. Li, M. F. Naylor, T. Hode, R. E. Nordquist, L. Alleruzzo, J. Raker, S. S. Lam, N. Du, L. Shi, X. Wang, W. R. Chen, "InCVAX-a novel strategy for treatment of late-stage, metastatic cancers through photoimmunotherapy induced tumor-specific immunity," Cancer Lett. 359, 169-177 (2015).

97. W. R. Chen, R. Carubelli, H. Liu, R. E. Nordquist, "Laser immunotherapy," Mol. Biotechnol. 25, 3743 (2003).

98. F. Zhou, S. Song, W. R. Chen, D. Xing, "Immunostimulatory properties of glycated chitosan," J. X-Ray Sci. Tech. 19, 285-292 (2011).

99. X. Li, M. Min, N. Du, Y. Gu, T. Hode, M. Naylor, D. Chen, R. E. Nordquist, W. R. Chen, "Chitin, chitosan, and glycated chitosan regulate immune responses: The novel adjuvants for cancer vaccine," Clin. Dev. Immunol. 2013, 387023 (2013).

100. S. Song, F. Zhou, R. E. Nordquist, R. Carubelli, H. Lui W. R. Chen, "Glycated chitosan as a new non-toxic immunological stimulant," Immunopharmacol. Immunotoxicol. 31, 202-208 (2009).

101. W. R. Chen, A. K. Singhal, H. Liu, R. E. Nordquist, "Laser immunotherapy induced antitumor immunity and its adoptive transfer," Cancer Res. 61, 459-461 (2001).

102. W. R. Chen, S. W. Jeong, M. D. Lucroy, R. F. Wolf, E. W. Howard, H. Liu, R. E. Nordquist, "Induced antitumor immunity against DMBA-4 metastatic mammary tumors in rats using laser immunotherapy," Inter. J. Cancer 107, 1053-1057 (2003).

103. W. R. Chen, Z. Huang, M. Korbelik, R. E. Nordquist, H. Liu, "Photoimmunotherapy for cancer treatment," J. Environ. Pathol. Toxicol. Oncol. 25, 281-291 (2006).

104. W. R. Chen, M. Korbelik, K. E. Bartels, H. Liu, J. Sun, R. E. Nordquist, "Enhancement of laser cancer treatment by a chitosan-derived immunoadjuvant," Photochem. Photobiol. 81, 190-195 (2005).

105. F. Zhou, X. Li, S. Song, J. T. Acquaviva III, R. F. Wolf, E. W. Howard, W. R. Chen, "Anti-tumor responses induced by laser irradiation and immunological stimulation using a mouse mammary tumor model," J. Innov. Opt. Heal. Sci. 6, 1350039 (2013).

106. W. R. Chen, W. Zhu, J. R. Dynlacht, H. Liu, R. E. Nordquist, "Long-term tumor resistance induced by laser photo-immunotherapy," Inter. J. Cancer 81, 808-812 (1999).

107. M. F. Naylor, W. R. Chen, T. K. Teague, L. Perry, R. E. Nordquist, "In situ photo immunotherapy: A tumor-directed treatment modality for melanoma," Br. J. Dermatol. 155, 1287-1292 (2006).

108. X. Li, G. L. Ferrel, M. C. Guerra, T. Hode, J. A. Lunn, O. Adalsteinsson, R. E. Nordquist, H. Liu, W. R. Chen, "Preliminary safety and efficacy results of laser immunotherapy for the treatment of metastatic breast cancer patients," Photochem. Photobiol. Sci. 10, 817-821 (2011).

109. X. Li, M. F. Naylor, H. Le, R. E. Norquist, T. K. Teague, C. A. Howard, C. Murray, W. R. Chen, "Clinical effects of in situ photoimmunotherapy on late-stage melanoma patients: A preliminary study," Cancer Biol. Ther. 10, 1081-1087 (2010).

110. X. Li, T. Hode, M. C. Guerra, J. A. Lunn, O. Adalsteinsson, R. E. Norquist, W. R. Chen, "photothermal therapy and immunoadjuvant against Stage IV breast cancer," Innov. Opt. Health Sci. 3, 279 (2010).

111. M. Korbelik, J. Sun, I. Cecic, K. Serrano, "Adjuvant treatment for complement activation increases the effectiveness of photodynamic therapy of solid tumors," Photochem. Photobiol. Sci. 3, 812-816 (2004).

112. U. Winters, S. Daayana, J. T. Lear, A. E. Tomlinson, E. Elkord, P. L. Stern, H. C. Kitchener, "Clinical and immunologic results of a phase II 
trial of sequential imiquimod and photodynamic therapy for vulval intraepithelial neoplasia," Clin. Cancer Res. 14, 5292-5299 (2008).

113. K. Le, X. Li, D. Figueroa, R. A. Towner, P. Garteiser, D. Saunders, N. Smith, H. Liu, T. Hode, R. E. Norquist, W. R. Chen, "Assessment of thermal effects of interstitial laser phototherapy on mammary tumors using proton resonance frequency method," J. Biomed. Opt. 16, 128001 (2011).

114. F. Zhou, S. Wu, S. Song, W. R. Chen, D. E. Resasco, D. Xing, "Antitumor immunologically modified carbon nanotubes for photothermal therapy," Biomaterials 33, 3235-3242 (2012).

115. L. Guo, D. D. Yan, D. Yang, Y. Li, X. Wang, O. Zalewski, B. Yan, W. Lu, "Combinatorial photothermal and immuno cancer therapy using chitosan-coated hollow copper sulfide nanoparticles," ACS Nano 8, 5670-5681 (2014).

116. T. G. St Denis, K. Aziz, A. A. Waheed, Y. Y. Huang, S. K. Sharma, P. Mroz, M. R. Hamblin, "Combination approaches to potentiate immune response after photodynamic therapy for cancer," Photochem. Photobiol. Sci. 10, 792-801 (2011).

117. M. Uehara, K. Sano, Z. L. Wang, J. Sekine, H. Ikeda, T. Inokuchi, "Enhancement of the photodynamic antitumor effect by streptococcal preparation OK-432 in the mouse carcinoma," Cancer Immunol. Immunother. 49, 401-409 (2000).

118. R. C. Myers, B. H. Lau, D. Y. Kunihira, R. R. Torrey, J. L. Woolley, J. Tosk, "Modulation of hematoporphyrin derivative-sensitized phototherapy with corynebacterium parvum in murine transitional cell carcinoma," Urology 33, 230-235 (1989).

119. M. Korbelik, I. Cecic, "Enhancement of tumour response to photodynamic therapy by adjuvant mycobacterium cell-wall treatment," J. Photochem. Photobiol. B. 44, 151-158 (1998).
120. M. Korbelik, J. Sun, J. J. Posakony, "Interaction between photodynamic therapy and BCG immunotherapy responsible for the reduced recurrence of treated mouse tumors," Photochem. Photobiol. 73, 403-409 (2001).

121. J. Gołab, G. Wilczyński, R. Zagozdzon, T. Stokłosa, A. Dabrowska, J. Rybczyńska, M. Wasik, E. Machaj, T. Ołda, K. Kozar, R. Kamiński, A. Giermasz, A. Czajka, W. Lasek, W. Feleszko, M. Jakóbisiak, "Potentiation of the anti-tumour effects of Photofrin-based photodynamic therapy by localized treatment with G-CSF," Br. J. Cancer 82, 1485-1491 (2000).

122. G. Krosl, M. Korbelik, J. Krosl, G. J. Dougherty, "Potentiation of photodynamic therapy-elicited antitumor response by localized treatment with granulocyte-macrophage colony-stimulating factor," Cancer Res. 56, 3281-3286 (1996).

123. D. A. Bellnier, "Potentiation of photodynamic therapy in mice with recombinant human tumor necrosis factor-alpha," J. Photochem. Photobiol B 8, 203-210 (1991).

124. E. E. Johnson, B. H. Yamane, I. N. Buhtoiarov, H. D. Lum, A. L. Rakhmilevich, D. M. Mahvi, S. D. Gillies, P. M. Sondel, "Radiofrequency ablation combined with KS-IL2 immunocytokine (EMD 273066) results in an enhanced antitumor effect against murine colon adenocarcinoma," Clin. Cancer Res. 15, 4875-4884 (2009).

125. M. Habibi, M. Kmieciak, L. Graham, J. K. Morales, H. D. Bear, M. H. Manjili, "Radiofrequency thermal ablation of breast tumors combined with intralesional administration of IL-7 and IL-15 augments anti-tumor immune responses and inhibits tumor development and metastasis," Breast Cancer Res. Treat. 114, 423-431 (2009). 